\title{
The influence of iodate ion additions to the bath on the deposition of electroless nickel on mild steel
}

\author{
S. Court, ${ }^{2}$ C. Kerr, ${ }^{2+}$ C. Ponce de León, ${ }^{1}$ B.D. Barker, ${ }^{2}$ J.R. Smith ${ }^{2}$ and F.C. Walsh ${ }^{1, *}$ \\ ${ }^{1}$ Electrochemical Engineering Laboratory, Engineering Sciences, University of Southampton, Highfield, \\ Southampton SO17 1BJ, UK \\ ${ }^{2}$ School of Pharmacy and Biomedical Sciences, University of Portsmouth, St Michael's Building, White Swan \\ Road, Portsmouth PO1 2DT, UK \\ + Current address: Atotech (China) Chemicals Ltd, Shanghai Qingpu Branch No. 5399, Plant A6, Wai Qing \\ Song Road, Qingpu District, Shanghai, China 201707 \\ * For correspondence; email: f.c.walsh@ soton.ac.uk
}

\begin{abstract}
An alkaline hypophosphite bath ( $0.1 \mathrm{M}$ nickel sulphate, $0.2 \mathrm{M}$ sodium hypophosphite, $0.2 \mathrm{M}$ sodium acetate and $0.1 \mathrm{M}$ malic acid, adjusted to $\mathrm{pH} 5$ ) was used to produce Ni-P coatings on uncoated and electroless nickel preplated mild steel. The deposition was monitored by open-circuit potential-time monitoring $v s$. a saturated calomel reference electrode and potentiostatic current-time monitoring together with anodic and cathodic polarisation. Classical mixed potential theory was applied to the polarisation data to calculate the effect of controlled iodate ion additions (0-1000 ppm) as an accelerator to the electrolyte on the plating rate. The mixed potential and deposition current density increased gradually with potassium iodate concentration. The use of electrochemical data allowed the optimum iodate additive concentration to be established using simple instrumentation.
\end{abstract}

Keywords: Current vs. time, potential vs. time; electroless nickel; immersion plating, polarisation data.

\section{Introduction}

Electroless nickel (EN) deposition is an open-circuit, mixed electrode process involving two electrochemical reactions taking place on the same surface, namely (a) the cathodic reduction of nickel ions $\left(\mathrm{Ni}^{2+}\right.$, cathodic) and, (b) the oxidation of the reducing agent, sodium hypophosphite, to sodium orthophosphate (anodic). The 'hydride process' is the accepted mechanism for the deposition of EN..$^{1,2}$ The overall redox process occurs on a suitable catalytic surface; for the reaction to continue, the EN deposit itself must be catalytic to the process.

The electroless deposition process is well described by the mixed potential theory. ${ }^{1-4}$ In a hypophosphite EN bath, two electrode reactions occur at identical rates on the same (mixed) electrode surface, namely the reduction of $\mathrm{Ni}^{2+}$ to metallic $\mathrm{Ni}$ and oxidation of hypophosphite to orthophosphite ions:

$$
\begin{aligned}
& \mathrm{Ni}^{2+}+2 \mathrm{e}^{-} \rightarrow \mathrm{Ni} \\
& \mathrm{H}_{2} \mathrm{PO}_{2}{ }^{-}+\mathrm{H}_{2} \mathrm{O} \rightarrow \mathrm{H}_{2} \mathrm{PO}_{3}{ }^{-}+2 \mathrm{H}^{+}+2 \mathrm{e}^{-}
\end{aligned}
$$

The electrons required for the reduction of the metal ions are supplied by the reducing agent and the overall rate of reaction is governed by the exchange current density, $j_{o}$. Initially, the potential $(E)$ of the anodic sites is governed by the hypophosphite/orthophosphite redox reaction and the cathodic sites due to the $\mathrm{Ni} / \mathrm{Ni}^{2+}$ redox reaction. As the deposition reaction continues, the potential of the cathodic sites decrease whilst the anodic potential $\left(E_{A}\right)$ increases to a point known as the deposition potential $\left(E_{m i x}\right)$, with the current flowing in the reaction known as $I_{d e p}$ (where the two Tafel lines intersect, Fig. 1). The influence of additives on the electroless deposition process can be studied by investigating $I$ vs. $E$ behaviour.

This steady state electrode potential, $E_{m i x}$ is removed from the equilibrium potential by the polarisation, $\eta$ :

$$
\begin{aligned}
& \eta=E_{C}-E_{\text {mix }} \\
& \eta=E_{\text {mix }}-E_{A}
\end{aligned}
$$




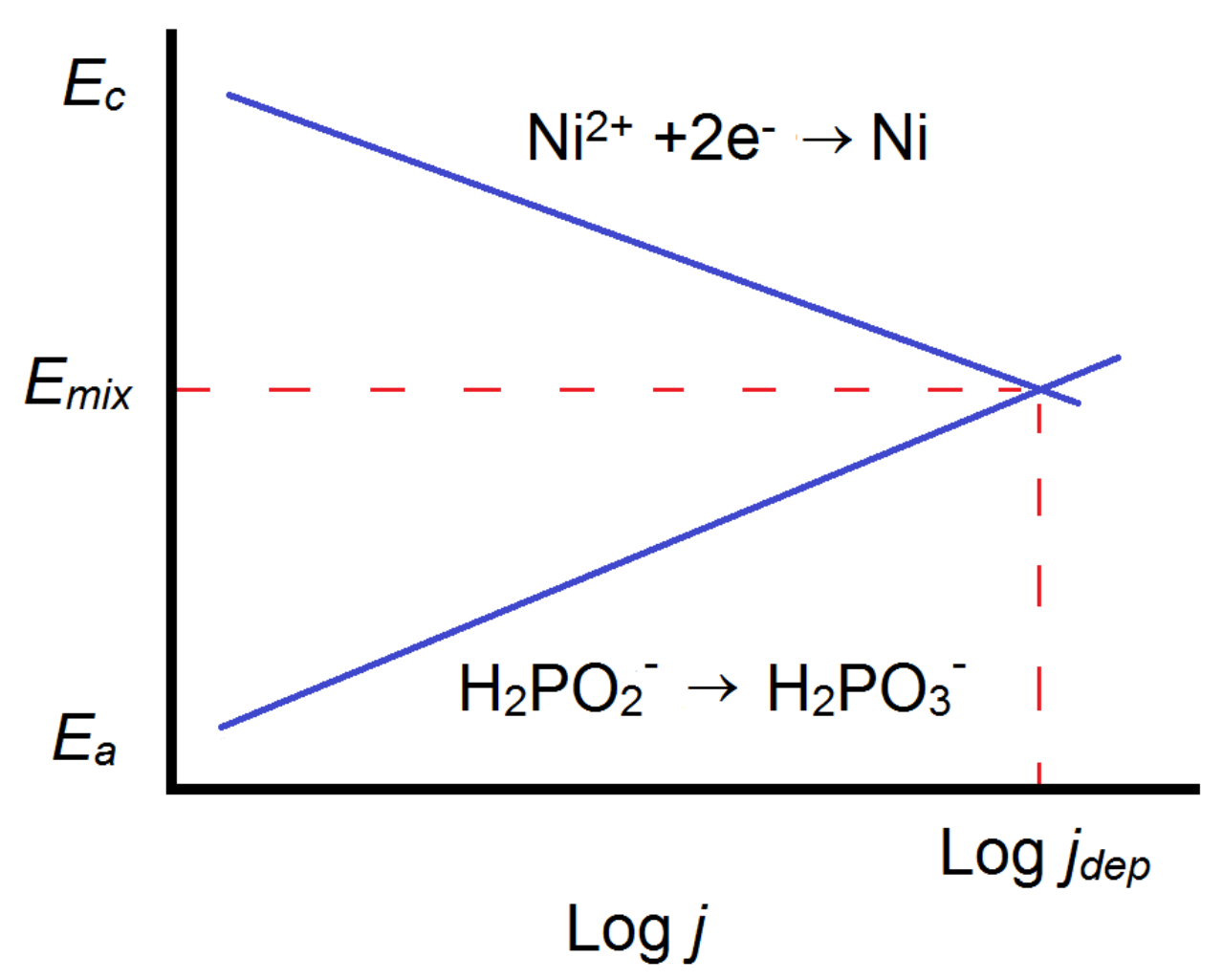

Fig. 1. Evans diagram showing the effect of hypophosphite ion on $E_{m i x}$ of the electrode at equilibrium.

The use of the mixed potential theory can be applied to the study of EN deposition by separating the partial electrode reactions. Anodic polarisation, in the absence of $\mathrm{Ni}^{2+}$ and cathodic polarisation, in the absence of hypophosphite ions, can be used to study this system.

\section{Determination of the mixed potential and the plating rate}

The mixed potential can be determined by the use of polarisation curves for the partial electrode reaction. ${ }^{2}$ Such polarisation curves can be obtained by several methods: ${ }^{4}$

(a) the application of the steady state galvanostatic or potentiostatic pulse method to each partial reaction separately,

(b) applying potential scanning techniques to a static or rotating disc electrode (RDE), and

(c) measurement of the plating rate from the mass gain as a function of the concentration of the reductant or oxidant. The plating rate is then plotted against $E_{m i x}$ to obtain the Tafel characteristics.

Paunovic used the mixed potential theory to study EN deposition using dimethylamine borane as the reducing agent. ${ }^{1}$ A Pt foil was used as the working electrode to obtain $I v s$. $E$ curves for the two partial reactions. $E_{m i x}$ and $I_{d e p}$ were obtained from the intersection of these curves.

Fang et al. used cathodic and anodic polarisations by linear sweep voltammetry on a freshly plated EN deposit on mild steel. ${ }^{5,6}$ The accelerating effect of thioglycolic acid and thiourea on the anodic processes was shown. Altura investigated both the cathodic and the anodic processes with bath inhibitors such as lead, thiourea, potassium iodate $\left(\mathrm{KIO}_{3}\right)$ and $\mathrm{Na}_{2} \mathrm{MoO}_{4}$ to show the effect on the mixed potential $E_{m i x}$ and $j_{m i x}$, current density at the mixed electrode. ${ }^{7}$

The effects of KI on a freshly plated mild steel electrode were shown by Keping et al. ${ }^{8}$ Linear sweep voltammetry indicated that the stabilisation effect inhibited the anodic reaction and this is due to adsorption of $\mathrm{I}^{-}$ions on the catalytic metal surface. 
Cathodic and anodic polarisation using an EN coated nickel RDE was studied by Das and Chin. ${ }^{9}$ The mixed potential and current density were determined by the intersection of the anodic and cathodic polarisation curves for four stabilisers, lead ion, $\mathrm{IO}_{3}^{-}$, mercaptobenzothiazole and maleic acid.

Bindra et al. used the mixed potential theory to look at the mechanism of electroless copper deposition at an RDE. ${ }^{4,10}$ Polarisation curves have also been obtained by the potentiostatic or galvanostatic step method.

\section{Polarisation resistance method}

Gabrielli and Raulin suggested that the polarisation resistance was directly related to the rate of EN deposition. ${ }^{11}$ The effects of temperature and dissolved oxygen on the deposition reaction at a mild steel RDE were studied. The results showed the inhibitive effect of dissolved oxygen. The polarisation resistance was measured by superimposing a square wave of frequency $0.4 \mathrm{~Hz}$ with a potentiostat on each side of $E_{\text {mix }}$ (plating potential) and observing the current on an oscilloscope. The decreasing value of polarisation resistance with increasing temperature was shown.

Ohno and Haruyama showed that the plating rate can be estimated in electroless systems of $\mathrm{Cu}, \mathrm{Ni}$ and $\mathrm{Co} .{ }^{12} \mathrm{It}$ was proposed that the deposition rate in electroless systems is inversely proportional to the linear polarisation resistance, which is similar to the Stern-Geary equation,

$$
1 / R_{\mathrm{p}}=I_{p 1} / K
$$

where $R_{p}$ is the polarisation resistance, $I_{p l}$ is the electroplating current and $K$ is the Stern-Geary constant.

Suzuki et al. described the coulostatic method, where a charged pulse is applied to the electrode to be plated and the potential decay curve is monitored. ${ }^{13,14}$ It was shown that the potential decay curve follows the equation

$$
\eta_{t}=\eta_{o}-t / 2.3 C_{d} R_{p}
$$

where $\eta_{t}=$ is the polarisation at time, $t, \eta_{o}$ is the polarisation after the initial pulse and $C_{d}$ is the double layer capacitance of the electrode, determined by

$$
C_{d}=q / \eta_{o}
$$

A plot of $\eta_{t} v s$. time yields a straight line from which the polarisation resistance can be measured, while the plating rate can then be determined by Eq. (5).

The more complex AC impedance method for determining the plating rate of EN deposition has been considered by Ohno. ${ }^{12}$

In general, an averaged, constant rate of plating can be expressed as a mass gain, $\Delta w$ in a time $t$, and related to the current, $I$ by Faraday's laws of electrolysis, assuming unity current efficiency:

$$
\frac{\Delta w}{t}=\frac{M}{z F} . I
$$

or, a thickness gain, $\Delta x$ can be related to the deposition current density, $j_{d e p}$ :

$$
\frac{\Delta x}{t}=\frac{M}{\rho z F} \cdot j_{d e p}
$$

$M$ is the molar mass of $\mathrm{Ni}\left(58.7 \mathrm{~g} \mathrm{~mol}^{-1}\right)$, the electron stoichiometry, $z=2, F$ is the Faraday constant (96 $485 \mathrm{~A} \mathrm{~s}$ $\left.\mathrm{mol}^{-1}\right)$ and $\rho$ is the density of $\mathrm{Ni}\left(8.91 \mathrm{~g} \mathrm{~cm}^{-3}\right)$.

\section{The effect of bath additives on EN plating}

Additives are commonly used in EN baths to improve the deposit quality. The most common additives include complexants, buffers, stabilisers and accelerators.

\section{Complexing agents}

Complexants prevent the precipitation of $\mathrm{Ni}$ salts and reduce the concentration of free $\mathrm{Ni}$ ions. Typical examples include potassium pyrophosphate, malic acid, lactic acid, glycolic acid, monocarboxylic acids, dicarboxylic acids, hydroxycarboxylic acids, ammonia and alkanolamines ${ }^{15}$ In addition, complexing agents also affect the deposition reaction often altering the phosphorus content of the $\mathrm{Ni}$ deposit and the structure of the deposit. ${ }^{16} \mathrm{Jin}$ et al. studied 
the effects of three complexing agents (sodium citrate, malic acid and lactic acid) on the morphology and porosity of deposits. ${ }^{17}$ It was noted that the porosity and surface roughness of mild steel substrates decreases with the increasing stability of the $\mathrm{Ni}$ complex.

$\mathrm{Ni}^{2+}$ in an aqueous solution are bound to six water molecules and have a co-ordination number of six. The complexing agent affects some of the chemical properties of the $\mathrm{Ni}^{2+}$ such as colour, ease of reduction and solubility. Mayanna studied the extent of complexation of $\mathrm{Ni}^{2+}$ by ethylenediamine and sodium potassium tartrate by cyclic voltammetry. ${ }^{18}$

Chelation of $\mathrm{Ni}^{2+}$ increases its resistance to precipitation and so it is possible to keep the $\mathrm{Ni}^{2+}$ in solution at a higher $\mathrm{pH}$ than would otherwise be possible. In aqueous solutions, chemical reactions with nickel ions take place with the co-ordination sites that are weakly bound to the water molecules. Therefore, the kinetics of the EN plating reactions free $\mathrm{Ni}^{2+}$ concentration (or activity) and the rate of $\mathrm{Ni}$ deposition is proportional to the rate at which the $\mathrm{Ni}$ complex dissociates to form free $\mathrm{Ni}^{2+}$. The plating rate is inversely related to the stability constant; at a lower rate of complex dissociation, the rate of deposition is reduced.

\section{Stabilisers}

In practice, the EN bath can operate for a long period of time but is subject to spontaneous decomposition. However, this problem can be virtually eliminated by the addition of trace amounts of catalytic inhibitors (stabilisers). Examples of such stabilisers include sodium citrate, compounds of group VI elements ( $\mathrm{S}, \mathrm{Se}, \mathrm{Te})$, inorganic oxyanions (e.g., $\mathrm{AsO}_{2}^{-}, \mathrm{IO}_{3}^{-}, \mathrm{MoO}_{4}^{2-}$, heavy metal cations (e.g. $\left.\mathrm{Sn}^{2+}, \mathrm{Pb}^{2+}, \mathrm{Hg}^{+}, \mathrm{Sb}^{3+}\right)$, unsaturated organic compounds (e.g., maleic and itaconic acids) and sulphur containing compounds (e.g., mercaptobenzothiazole and thiourea). ${ }^{9}$

It is well known that the addition of stabilisers decreases the plating rate and, beyond certain concentrations, inhibit the process completely. According to Das and Chin, some stabilisers, especially heavy metal and sulphur compounds, co-deposit along with the $\mathrm{Ni}$ and lower the corrosion resistance of the deposit. ${ }^{9}$ It was also noted that on ferrous substrates, the increase in stabiliser concentration increases porosity of the deposit. When maleic acid was used as the stabiliser, the phosphorus content of the deposit was decreased.

The stabilising effects can be divided into two categories. ${ }^{5,8,19}$ One is a substitution type mechanism where some heavy metal ions such as $\mathrm{Cd}^{2+}$, lead, $\mathrm{Hg}^{2+}, \mathrm{Sn}^{2+}$ and $\mathrm{Fe}^{2+}$ can be deposited on the active metal surface through a displacement reaction that inhibits the occurrence of the random reduction of Ni. The other is an adsorption type mechanism whereby anodic ion stabilisers (e.g., hydrogen sulphide, arsenide and iodide $\mathrm{I}^{ }$) can inhibit the $\mathrm{Ni}$ deposition via adsorption on the catalytic sites on the metal surface.

Keping and Fang studied the effect of thiourea on mild steel. ${ }^{6}$ It was proposed that the presence of thiourea on the catalytic sites of the metallic substrate hinder the access of the hypophosphite ion. This inhibits the oxidation process and the production of atomic hydrogen which, in turn, affects the production of $\mathrm{H}_{2}$ and therefore the $\mathrm{Ni}$ deposition. They found a similar type of mechanism for $\mathrm{I}^{-8}$

Buffers are added to stabilise the $\mathrm{pH}$. Variations in $\mathrm{pH}$ during plating may alter the rate of deposition and could change the phosphorus content of the deposit. Examples of buffers include citric acid and sodium salts of certain complexants (depending on the $\mathrm{pH}$ range).

Wetting agents increase the wettability of surfaces to be coated and reduce streaking caused by the formation of $\mathrm{H}_{2}$. Examples include ionic and nonionic surfactants.

Examples of accelerators include carboxylic acids, thioglycolic acid, borates, thiourea, fluorides, glycine and formate. The function of accelerators is to activate hypophosphite ions and accelerate the deposition reaction. This action is in opposition to stabilisers and complexants. Fang and Han studied the acceleration mechanism of thioglycolic acid and found that the additive was absorbed onto the surface and accelerated both the anodic and cathodic reaction. ${ }^{5}$ Cystine was shown to have an accelerating effect by reducing the activation energy of the anodic process. ${ }^{20}$ The effects on polarisation curves indicated that the oxidation of hypophosphite was accelerated during EN deposition.

\footnotetext{
Aims

The present research makes use of the mixed potential theory to investigate the effects of additives on EN plating. $\mathrm{KIO}_{3}$, a known EN stabiliser, is used to show its role in the plating bath by considering the individual anodic and cathodic polarisation curves. Extrapolation of the Tafel regions (Fig. 1) leads to the determination of the mixed
} 
electrode potential, $E_{m i x}$ and deposition current density, $j_{d e p}$. The plating rate can be calculated from Eq. (9) and compared to mass gain analysis using Eq. (8). Stabilisers have also been shown to decrease the corrosion resistance of EN deposits and this is investigated on deposits plated at controlled concentrations of $\mathrm{KIO}_{3}$ in the bath, by Tafel analysis and anodic polarisation.

\section{Experimental}

\section{Substrates}

Pyrene steel $(0.10-0.12 \mathrm{wt} \% \mathrm{C},<0.040 \mathrm{wt} \% \mathrm{~S},<0.040 \mathrm{wt} \% \mathrm{P},<0.050 \mathrm{wt} \% \mathrm{Mn}$, balance being Fe) samples were cut to size $\left(10 \times 2 \times 0.1 \mathrm{~cm}^{3}\right)$. The rotating disc electrode $(\mathrm{RDE})$ was constructed from mild steel $(0.10-0.15 \mathrm{wt} \%$ C, 0.3-0.5 wt \% Mn, balance being Fe) rod (A40A12, $\left.0.196 \mathrm{~cm}^{2}\right)$ coated with PVDF, with a brass thread inserted to make electrical contact with the rotator. This electrode was coated with Fidelity 5010 electroless nickel (OMG Fidelity, South Plainfield, NJ, USA; 5 h, details below), when an EN RDE was required.

\section{Plating rate and the pre-treatment process}

Prior to the pre-treatment process, pyrene steel samples were cleaned with methanol and dried, to remove temporary protective films used in packaging. $10 \times 2 \times 0.1 \mathrm{~cm}^{3}$ panels were degreased in an alkaline soak cleaner (Fidelity 3152) at a concentration of $10 \% \mathrm{w} / \mathrm{v}$ for $10 \mathrm{~min}$ at $50-60{ }^{\circ} \mathrm{C}$. A double water rinse in deionised water for $1 \mathrm{~min}$ was carried out and after all pre-treatment stages. Immersion in a solution of $50 \% \mathrm{HCl}$ for $2 \mathrm{~min}$ at 22 ${ }^{\circ} \mathrm{C}$ was used to remove surface oxides. The plating rate was determined after $30 \mathrm{~min}$ by mass gain analysis in EN baths containing: $0.1 \mathrm{M} \mathrm{NiSO}_{4}, 0.2 \mathrm{M}$ sodium hypophosphite, $0.2 \mathrm{M}$ sodium acetate, $0.1 \mathrm{M}$ malic acid and adjusted to $\mathrm{pH} 5$ using $2.5 \mathrm{M} \mathrm{NaOH}$.

\section{Mixed potential analysis at static electrodes}

A Princeton EG \& G potentiostat (model 273A) with a linear sweep rate of $1 \mathrm{mV} \mathrm{s}^{-1}$ was used for the mixed potential analysis. Pyrene steel (which had been covered using a polymer insulating tape with a $1 \mathrm{~cm}^{2}$ hole cut into it) was plated with EN for $30 \mathrm{~min}$ in the plating bath, as detailed above. The plating bath contained no additives to ensure repeatability of the surface. Pyrene steel panels that had not been plated, but had undergone the pre-treatment process, were also studied. The panels were rinsed with deionised water and placed in a threecompartment electrochemical cell (Fig. 2). A saturated calomel reference electrode (SCE) and platinum mesh counter electrode $\left(3 \mathrm{~cm}^{2}\right)$ was used. The specimen was placed in the cell in the following electrolyte for the cathodic polarisation at $90{ }^{\circ} \mathrm{C}: 0.1 \mathrm{M} \mathrm{NiSO}_{4}$ and $0.1 \mathrm{M}$ malic acid together with 0-600 $\mathrm{ppm} \mathrm{KIO}_{3}$ adjusted to $\mathrm{pH}$ 5 using $2.5 \mathrm{M} \mathrm{NaOH}$.

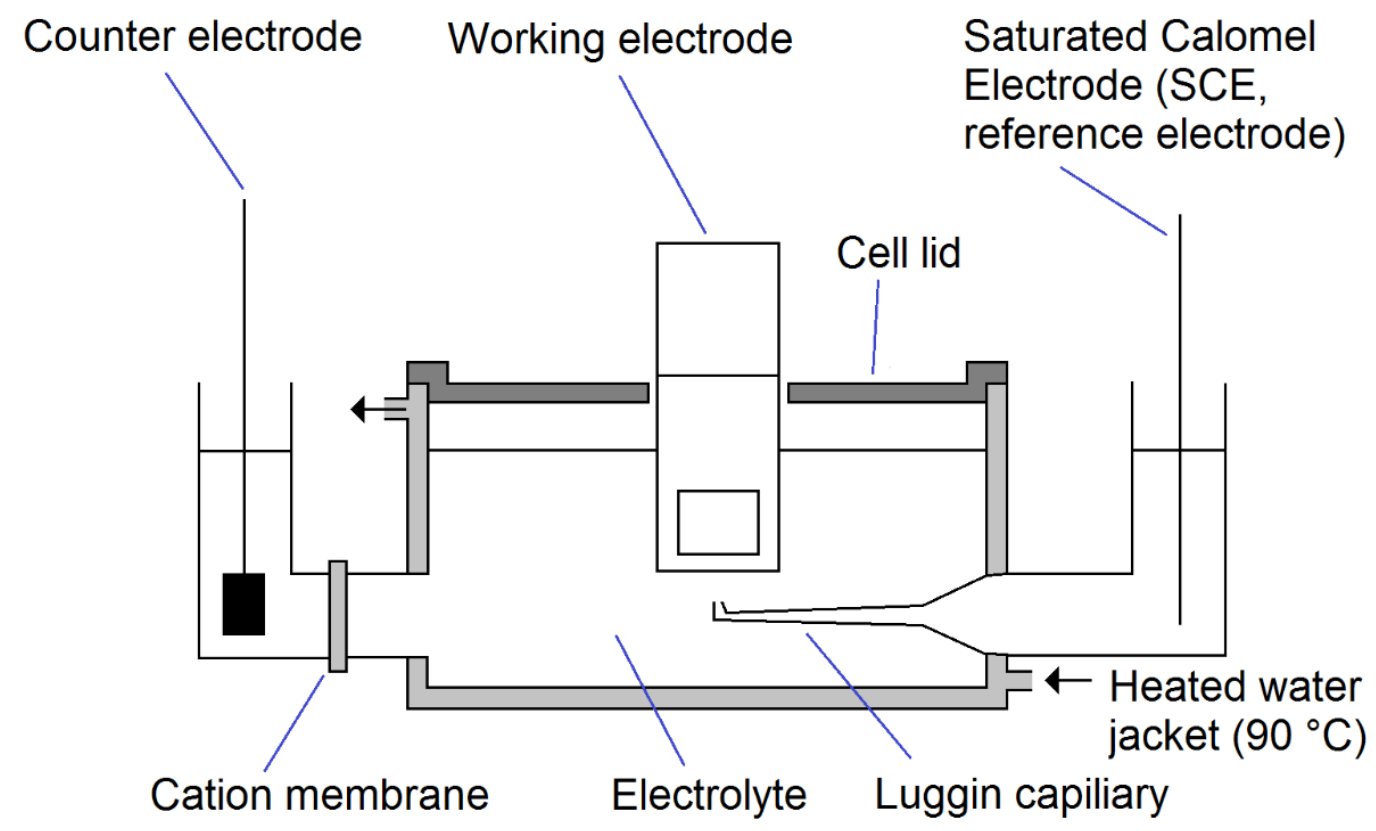

Fig. 2. The glass, divided, three-electrode electrochemical cell for RDE studies. 
The anodic polarisation was carried out at $90{ }^{\circ} \mathrm{C}$ in an electrolyte containing $0.2 \mathrm{M}$ sodium hypophosphite , 0.1 $\mathrm{M}$ malic acid and 0-600 ppm $\mathrm{KIO}_{3}$ adjusted to $\mathrm{pH} 5$ using $2.5 \mathrm{M} \mathrm{NaOH}$.

\section{Mixed potential analysis at a rotating disc electrode}

A Pine RDE (Grove City, PA, USA) at a rotation speed of $500 \mathrm{rpm}$ was used to simulate plating conditions. Two electrodes were used for the analysis, EN plated mild steel which had been plated for $5 \mathrm{~h}$ in Fidelity 5010 to give a thickness of $c a .25 \mu \mathrm{m}$, and mild steel. Prior to mixed potential analysis the electrodes were wet-polished using Buehler Microcloth ${ }^{\circledR}$ PSA and progressively finer alumina $\left(\mathrm{Al}_{2} \mathrm{O}_{3} ; 3 \mu \mathrm{m}\right.$ down to $\left.0.3 \mu \mathrm{m}\right)$. The electrodes were then well rinsed and polished on the polishing cloth in the absence of $\mathrm{Al}_{2} \mathrm{O}_{3}$ to ensure that no polishing media remained on the electrode surface.

\section{Anodic polarisation in the presence of $\mathrm{KIO}_{3}$ additions}

Tafel and anodic polarisation was carried out to investigate whether additions of the additive had any effect on the corrosion resistance of the deposit. A Princeton EG \& G potentiostat (model 273A) with was used for the anodic polarisation with the samples being polarised from -250 to $+1600 \mathrm{mV} v s$. SCE at a potential weep rate of $1 \mathrm{mV} \mathrm{s}^{-1}$. The reference electrode was an SCE with a platinum mesh counter electrode of $4 \mathrm{~cm}^{2}$. Mild steel was plated with EN for 30 min with increasing concentrations of $\mathrm{KIO}_{3}$ in the plating bath.

\section{Results and discussion}

\section{Mixed potential analysis on static electrodes}

\section{Effect of $\mathrm{KIO}_{3}$ additions on a fresh EN deposit}

The addition of $\mathrm{KIO}_{3}$ on a freshly plated EN deposit had an effect on the anodic and cathodic polarisation curves (Figs. 3a and b). For the anodic polarisation curves, the main difference was the change in the open-circuit electrode potential with $\mathrm{KIO}_{3}$ concentration (Fig. 3c). $E$ values rose from $-739 \mathrm{mV}$ to $-484 \mathrm{mV}$ vs. SCE as the stabiliser was increased from 0 to $100 \mathrm{ppm}$. Above this $\mathrm{KIO}_{3}$ concentration, there was only a slight increase in potential. Apart from the disappearance of the first 'nose' on the polarisation plots, there was no noticeable difference in the anodic currents over the range of stabiliser additions investigated.

The mechanism of $\mathrm{IO}_{3}{ }^{-}$stabilisation probably involves poisoning of hypophosphite reduction. This may be due to either the formation of an adsorbed species on the metal surface blocking the reaction or the inhibition of the anodic reaction attributed to chemical breakdown of the additive and hypophosphite. The reduction in current suggests that adsorption of $\mathrm{IO}_{3}{ }^{-}$ions ${ }^{9}$ is more probable than the poisoning on the oxidation reaction in slowing down the plating rate.

The cathodic polarisation curves showed a similar increase in open-circuit potential (Fig. $3 b$ ). $E$ values here increased from $-612 \mathrm{mV}$ with no additive to $-506 \mathrm{mV}$ in the presence of $100 \mathrm{ppm}$ of stabiliser. There was also a significant alteration to the shape of the cathodic polarisation plot. In the absence of $\mathrm{KIO}_{3}$, the cathodic plot was typical of a reduction of $\mathrm{Ni}^{2+}$ to the metal with the associated evolution of $\mathrm{H}_{2}$. When $100 \mathrm{ppm} \mathrm{KIO}_{3}$ was added, the starting potential became more noble and a limiting current was observed (Fig. $3 \mathrm{~b}$ ). When $E$ reached that of the unstabilised solution ( $-650 \mathrm{mV}$ vs. SCE), the scan followed an almost identical path. Further additions of $\mathrm{KIO}_{3}$ produced similar scans until $600 \mathrm{ppm}$. The limiting current density remained until a potential of $-750 \mathrm{mV} v \mathrm{~s}$. SCE was reached, where there was an increase in current. From mass gain measurements, this was the level of stabiliser at which no significant rate of EN deposition was observed.

This limiting current at higher levels of $\mathrm{KIO}_{3}$ could be due to the reduction of $\mathrm{IO}_{3}{ }^{-}$ions in preference to $\mathrm{Ni}^{2+}$ ions, as reflected in the Pourbaix diagram for iodine-water, ${ }^{21}$ where at more negative potentials, $\mathrm{IO}_{3}{ }^{-}$can be reduced to I' ions:

$$
\mathrm{IO}_{3}{ }^{-}+6 \mathrm{H}^{+}+6 \mathrm{e}^{-} \rightarrow \mathrm{I}^{-}+3 \mathrm{H}_{2} \mathrm{O} \quad \mathrm{E}^{\circ}=+0.549 \mathrm{~V} \text { vs. SCE }
$$

When the potential reached that of the unstabilised solution $(-650 \mathrm{mV})$, the scan followed an almost identical path. Further additions of $\mathrm{KIO}_{3}$ produced similar polarisation curves until a concentration of 600 ppm was reached. The limiting current density remained steady until $E=-750 \mathrm{mV}$, where there was an increase in current, this being at the level of stabiliser (600 ppm) at which no EN deposition was observed. 


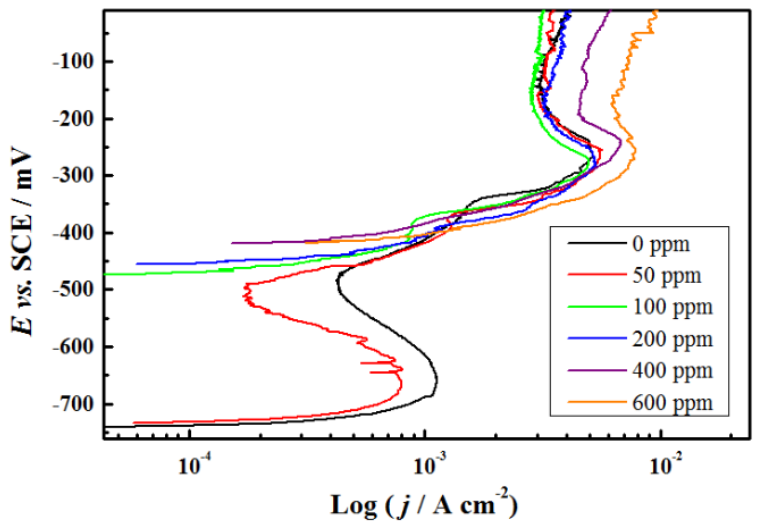

(a)

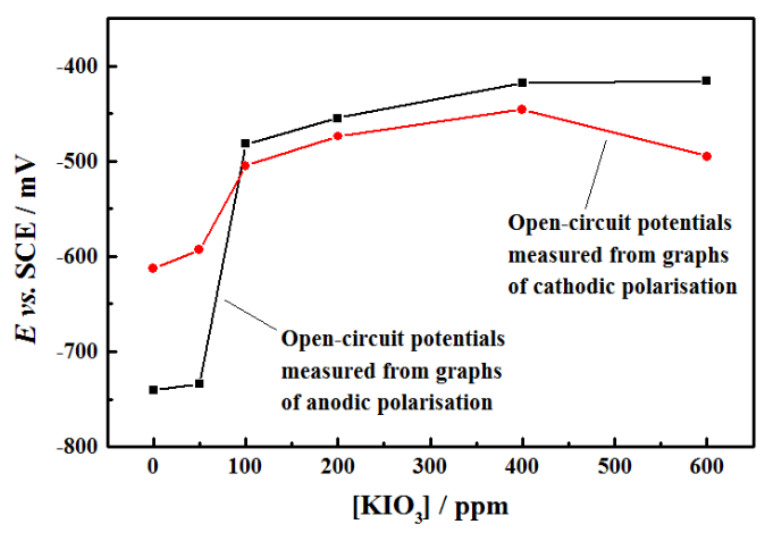

(c)

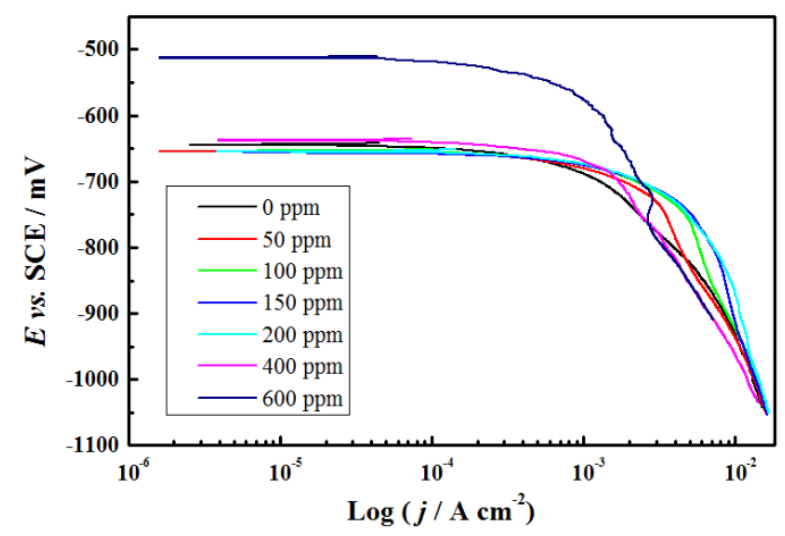

(e)

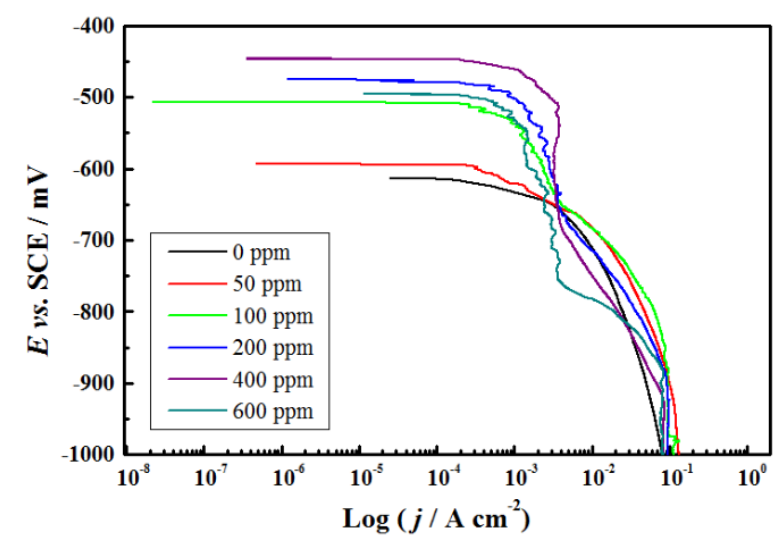

(b)

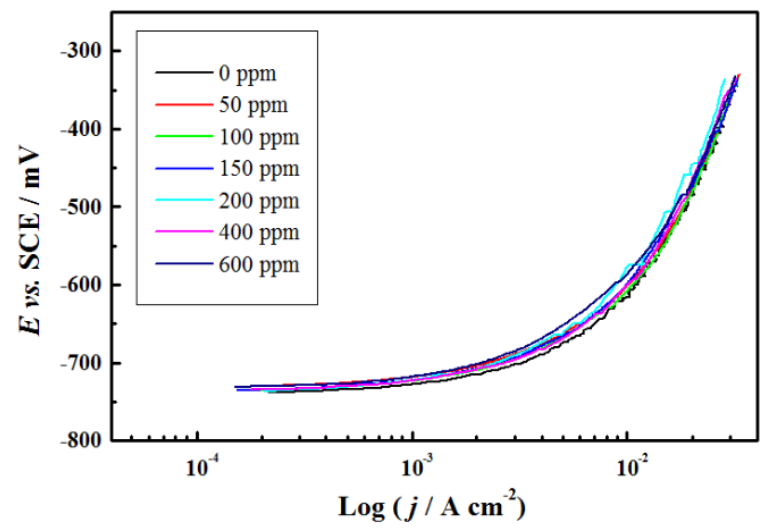

(d)

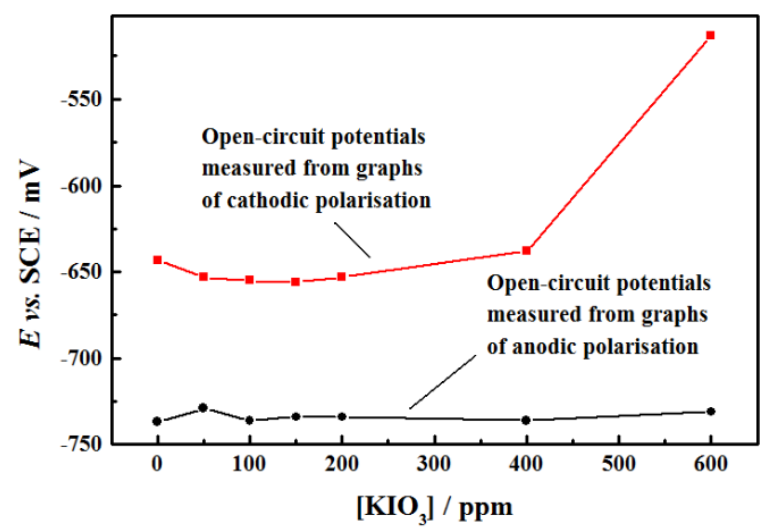

(f)

Fig. 3. (a) Anodic and (b) cathodic polarisation data obtained from a freshly plated EN (deposited for $30 \mathrm{~min}$ ) pyrene steel surface (static electrode) in a $\mathrm{NiSO}_{4}$ electrolyte at $90{ }^{\circ} \mathrm{C}$ in sodium hypophosphite (sweep rate $=1$ $\mathrm{mV} \mathrm{s}{ }^{-1}$ ), and (c) open-circuit electrode potentials taken from anodic and cathodic polarisation plots. $\mathrm{KIO}_{3}$ concentrations indicated. (d-f) Show similar plots to (a-c) except that the pyrene steel has not been EN coated.

$\mathrm{IO}_{3}{ }^{-}$is known to be reduced in solution by hypophosphite (Eq. 11), which can be further reduced to $\mathrm{I}_{2}$ in acidic conditions (Eqs. 12), leading to an overall reaction (Eq. 13): ${ }^{22}$

$$
\begin{aligned}
& \mathrm{IO}_{3}{ }^{-}+3 \mathrm{H}_{2} \mathrm{PO}_{2}^{-} \rightarrow \mathrm{I}^{-}+3 \mathrm{H}_{2} \mathrm{PO}_{3}^{-} \\
& \mathrm{IO}_{3}{ }^{-}+5 \mathrm{I}^{-}+6 \mathrm{H}^{+} \rightarrow 3 \mathrm{I}_{2}+3 \mathrm{H}_{2} \mathrm{O}
\end{aligned}
$$




$$
2 \mathrm{IO}_{3}{ }^{-}+5 \mathrm{H}_{2} \mathrm{PO}_{2}{ }^{-}+2 \mathrm{H}^{+} \rightarrow \mathrm{I}^{-}+5 \mathrm{H}_{2} \mathrm{PO}_{3}{ }^{-}+\mathrm{H}_{2} \mathrm{O}
$$

The extent to which these reactions play a role in the stabilisation (at $\mathrm{pH} 5$ ) is uncertain. There have been anecdotal reports of $\mathrm{IO}_{3}{ }^{-}$stabilisers for use in EN baths, after a period of time in use or in storage, producing $\mathrm{I}^{-}$ions $\left(v i a \mathrm{I}_{2}\right)$.

\section{Effect of $\mathrm{KIO}_{3}$ additions on pyrene steel}

The effect of adding $\mathrm{KIO}_{3}$ on the anodic and cathodic polarisation curves on pyrene steel was then investigated (Figs. $3 \mathrm{~d}$ and e). For the anodic curves, there was little difference in the open circuit potentials ( $c a .-730 \mathrm{mV} v s$. SCE) and shape of the traces with changes in $\left[\mathrm{KIO}_{3}\right]\left(50-600 \mathrm{ppm}\right.$; noise in some of traces attributed to $\mathrm{H}_{2}$ evolution). This was compared to an EN coated surface, where there was an increase in the open-circuit potential to $\left[\mathrm{KIO}_{3}\right]=100 \mathrm{ppm}$, followed by a plateau. The potential remained constant at $c a .-730 \mathrm{mV}$ over the full range of stabiliser concentration. There was no noticeable difference in anodic currents over the range of stabiliser additions investigated, suggesting $\mathrm{IO}_{3}{ }^{-}$ions were being adsorbed on the pyrene steel substrate.

The cathodic polarisation curves showed a similar trend in open circuit potential up to $200 \mathrm{ppm} \mathrm{KIO}_{3}$ (Fig. 3f). Below this level, the corrosion potential remained constant ( $c a .-650 \mathrm{mV} v$ s. SCE). Above $200 \mathrm{ppm}$, the potential increased from $-653 \mathrm{mV} v$ s. SCE to $-638 \mathrm{mV}$ and $-513 \mathrm{mV}$ with 400 and $600 \mathrm{ppm} \mathrm{KIO}_{3}$, respectively, with a significant to change in shape of the cathodic plot (Fig. 3e). In the absence of $\mathrm{KIO}_{3}$, the cathodic plot was typical for a reduction of $\mathrm{Ni}^{2+}$ to the metal. When $\mathrm{KIO}_{3}$ was added, the starting potential for the scan remained constant.

\section{Mixed potential analysis}

Combining the anodic and cathodic polarisation curves (Appendix 1) allowed values of $E_{m i x}$ and $j_{d e p}$ for each solution at the freshly deposited EN and pyrene steel substrates to be determined (Table 1). On the EN electrode, $E_{m i x}$ increased from $-663 \mathrm{mV}$ to $c a .-430 \mathrm{mV}$ vs. SCE after $100 \mathrm{ppm} \mathrm{KIO}_{3}$ had been added. Higher $\mathrm{KIO}_{3}$ levels did not lead to any real significant difference in $E_{\text {mix }}$ (Table 1a). The value of $j_{d e p}$ fell slightly from $4.38 \mathrm{~mA} \mathrm{~cm}{ }^{-2}$ without the additive to $4.15 \mathrm{~mA} \mathrm{~cm}^{-2}$ in the presence of $50 \mathrm{ppm} \mathrm{KIO}_{3}$. At $100 \mathrm{ppm}$, $j_{d e p}$ dropped quickly to 0.24 $\mathrm{mA} \mathrm{cm}{ }^{-2}$ and remained near this value with further stabiliser additions, suggesting a critical concentration had been reached.

Table 1. Plating rates determined from the deposition current density $\left(j_{d e p}\right)$ calculated from the mixed potential $\left(E_{m i x}\right)$ theory and mass gain experiments (at various $\mathrm{KIO}_{3}$ concentrations) at (a) a freshly deposited EN substrate, and (b) a pyrene steel electrode (both static electrodes).

\begin{tabular}{|c|c|c|c|c|}
\hline$\left[\mathrm{KIO}_{3}\right] / \mathrm{ppm}$ & $j_{\text {dep }} / \mathrm{mA} \mathrm{cm}^{-2}$ & $\begin{array}{c}E_{m i x} \\
\text { vs. } \mathrm{SCE} / \mathrm{mV}\end{array}$ & $\begin{array}{l}\text { Plating rate }{ }^{\mathrm{a}}, \\
\Delta x / t / \mu \mathrm{m} \mathrm{h}^{-1}\end{array}$ & $\begin{array}{l}\text { Plating rate }^{\mathbf{b}}, \\
\Delta x / t / \mu \mathrm{m} \mathrm{h}^{-1}\end{array}$ \\
\hline \multicolumn{5}{|l|}{ (a) } \\
\hline 0 & 4.38 & -663 & 6.10 & 14.2 \\
\hline 50 & 4.15 & -654 & 5.79 & 14.2 \\
\hline 100 & 0.24 & -462 & 0.34 & 14.0 \\
\hline 200 & 0.59 & -428 & 0.82 & 13.0 \\
\hline 400 & 0.21 & -433 & 0.29 & 9.2 \\
\hline 600 & 0.42 & -439 & 0.58 & 1.4 \\
\hline \multicolumn{5}{|l|}{ (b) } \\
\hline 0 & 1.72 & -719 & 2.40 & 14.2 \\
\hline 50 & 1.96 & -703 & 2.73 & 14.2 \\
\hline 100 & 2.36 & -704 & 3.29 & 14.0 \\
\hline 150 & 2.38 & -703 & 3.31 & 13.5 \\
\hline 200 & 2.46 & -701 & 3.43 & 13.0 \\
\hline 400 & 1.84 & -695 & 2.56 & 9.2 \\
\hline 600 & 2.32 & -692 & 3.23 & 1.4 \\
\hline
\end{tabular}

${ }^{a}$ From polarisation data; ${ }^{\mathrm{b}}$ From mass gain data 
At the pyrene steel electrode, $E_{m i x}$ shifted more positive from -719 to $c a$. $-700 \mathrm{mV}$ vs. SCE as the $\mathrm{KIO}_{3}$ concentration increased to $200 \mathrm{ppm}$ (Table 1b). At higher concentrations, $E_{\text {mix }}$ further increased to $-692 \mathrm{mV} v s$. $\mathrm{SCE}$ at $600 \mathrm{ppm}$, although $j_{\text {dep }}$ increased slightly as stabiliser was added and remained at $c a .2 \mathrm{~mA} \mathrm{~cm}$ as the concentration was increased. No specific trends were seen and this was reflected in the calculated plated rate, which remained constant at around $3 \mu \mathrm{m} \mathrm{h}^{-1}$.

Keping et al. used cathodic and anodic polarisation curves on a freshly plated EN electrode on mild steel to study the effects of KI. ${ }^{8}$ The polarisation curves showed a decrease in anodic currents with increasing [KI] that lead to the conclusion that the hypophosphite reaction was being inhibited due to adsorption of $\mathrm{I}^{-}$ions on the catalytic metal surface. The adsorption of $\mathrm{I}^{-}$ions also affected $E_{d e p}$ that was shown to shift to more noble potentials with increasing [KI].

Altura investigated both the cathodic and anodic processes with bath inhibitors such as lead, thiourea, $\mathrm{KIO}_{3}$ and sodium molybdate to show the effect on $E_{m i x}$ and $j_{d e p} .{ }^{7}$ Similar results were reported to those from the current investigation; $j_{d e p}$ reported by Altura decreased from 4.2 to $1.9 \mathrm{~mA} \mathrm{~cm}^{-2}$ at $[\mathrm{KI}]=400 \mathrm{ppm}$, whereas, in the current study, $j_{\text {dep }}$ decreased from 4.38 to $0.421 \mathrm{~mA} \mathrm{~cm}^{-2}$. It was proposed that at $[\mathrm{KI}]>100 \mathrm{ppm}$, the cathodic reaction was more likely to be the reduction of $\mathrm{IO}_{3}{ }^{-}$ions rather than that of $\mathrm{Ni}^{2+}$. This would account for the reduction in $j_{d e p}$ and the positive shift in $E_{m i x}$.

\section{Mixed potential analysis at a rotating disc electrode}

Plating rates determined from the extrapolation of the polarisation curves (derived from $j_{d e p}$ ) were different to those determined from mass gain analysis (Table 1 and Appendix 2). This could be due to the currents for $\mathrm{H}_{2}$ evolution and phosphorus deposition not being taken into account. However, if the deposition reaction for EN is under mixed control, the Tafel region would be small, but this can be extended using an RDE. This experimental procedure will increase rates of diffusion and thus minimise concentration polarisation effects at low values of overpotential.

The Tafel equations can be used to determine the kinetics for a purely charge transfer controlled reaction, however, the kinetics of a reaction rely on other factors, such as the rate of mass transport (the supply of reactants to an electrode surface and coincides with the removal of products) $;{ }^{23,24}$ diffusion, convection and migration contribute to these.

On a freshly deposited EN electrode, the data from the polarisation scans would suggest that $100 \mathrm{ppm}^{\mathrm{KIO}} \mathrm{O}_{3}$ would cause a significant reduction in plating rate (Table 1a). On a mild steel electrode, however, the deposition current also does not reflect the plating rate (Table $1 \mathrm{~b})$. Practical plating rate measurements via mass gain experiments indicate that the rate only starts to drop at $\left[\mathrm{KIO}_{3}\right]>400 \mathrm{ppm}$ and almost ceases at $600 \mathrm{ppm}$ (Table 1). This is most likely due to the limiting current densities observed in the cathodic plots for $\left[\mathrm{KIO}_{3}\right]>50 \mathrm{ppm}$, invalidating the extrapolation method for determining plating rates.

To simulate plating conditions, the effect of adding $\mathrm{KIO}_{3}$ on the anodic and cathodic polarisation curves was carried out using an RDE. The effects due to agitation used in EN baths could then be investigated under reproducible flow conditions. The polarisation curves were carried out using two electrodes: a mild steel RDE coated with high phosphorus EN, and the same mild steel RDE without the EN coating.

\section{Effect of $\mathrm{KIO}_{3}$ additions on high porous $\mathrm{EN}$ coated mild steel $\mathrm{RDE}$}

As the $\left[\mathrm{KIO}_{3}\right]$ increased, a shift in the open-circuit potential, from $-471 \mathrm{mV}$ to $-402 \mathrm{mV} v s$. SCE, was observed (Fig. 4a,b). The values of this property gradually shifted to more positive potentials ( $-360 \mathrm{mV} v s$. SCE) as $\left[\mathrm{KIO}_{3}\right]$ increased to $600 \mathrm{ppm}$ (Fig. 4a). As the potential increases, a limiting current density was reached that decreased with higher $\left[\mathrm{KIO}_{3}{ }^{-}\right]$. This is consistent with oxidation of hypophosphite becoming more difficult with increased $\left[\mathrm{KIO}_{3}{ }^{-}\right]$, suggesting that $\mathrm{IO}_{3}{ }^{-}$is becoming adsorbed on to the EN surface. $\mathrm{If} \mathrm{IO}_{3}{ }^{-}$is being oxidised then the limiting current will be increased. This is reflected in the open-circuit potential becoming more noble with increased $\left[\mathrm{KIO}_{3}{ }^{-}\right.$ ], due to the surface modification of $\mathrm{IO}_{3}{ }^{-}$ions (Fig. 4c).

The cathodic polarisation curves showed that when $\mathrm{KIO}_{3}$ was added to the electrolyte there was a gradual shift in open-circuit potential from $-433 \mathrm{mV}$ to $-380 \mathrm{mV}$ vs. SCE as $\left[\mathrm{KIO}_{3}\right]$ increased to $600 \mathrm{ppm}$ (Fig. 4b). As the potential increased, limiting current densities were reached that increased with increasing $\left[\mathrm{KIO}_{3}\right]$, indicating that $\mathrm{IO}_{3}{ }^{-}$was not adsorbed onto the cathodic sites. Since the limiting current was increasing with increasing $\left[\mathrm{KIO}_{3}\right]$, this suggests that is it being reduced in preference to $\mathrm{Ni}^{2+}$ ions. 


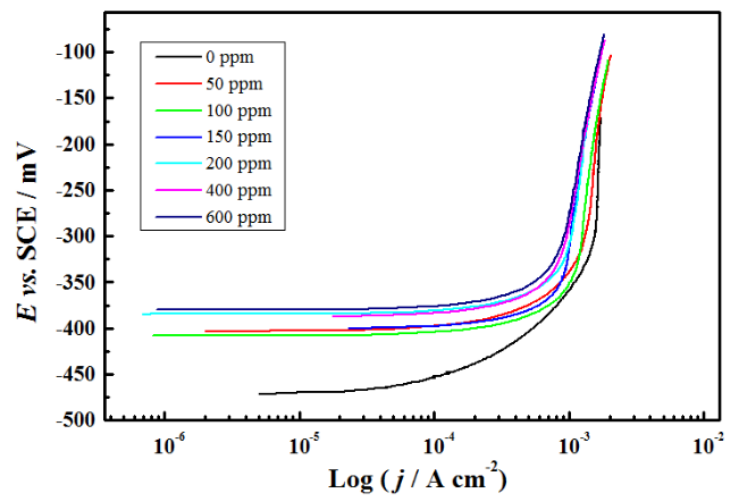

(a)

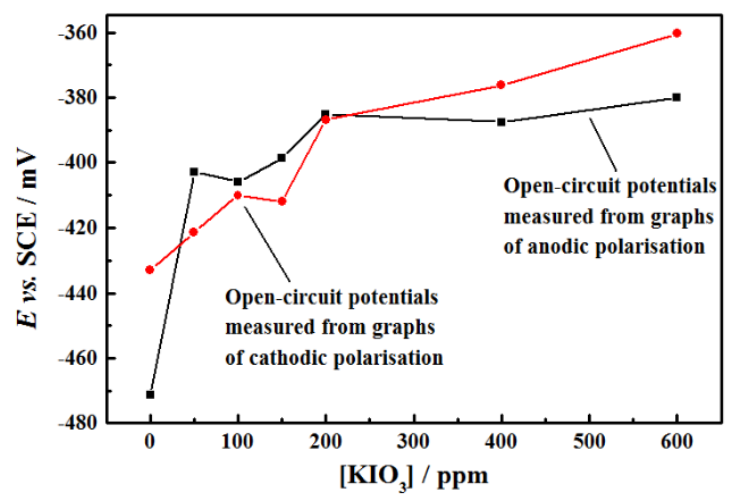

(c)

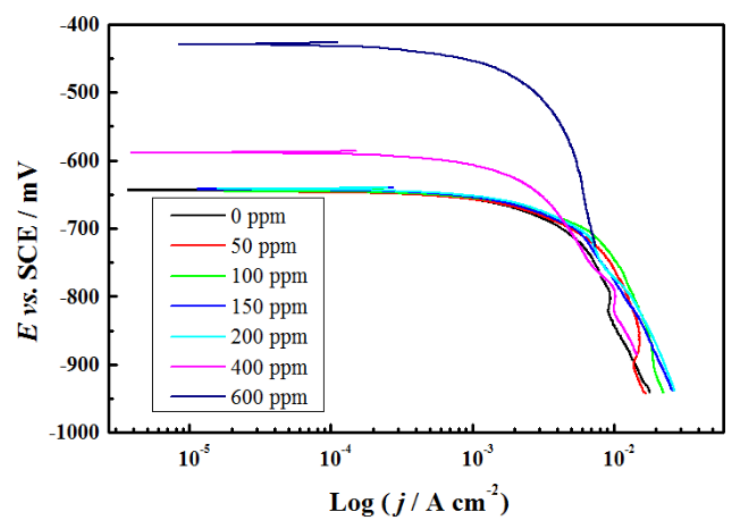

(e)

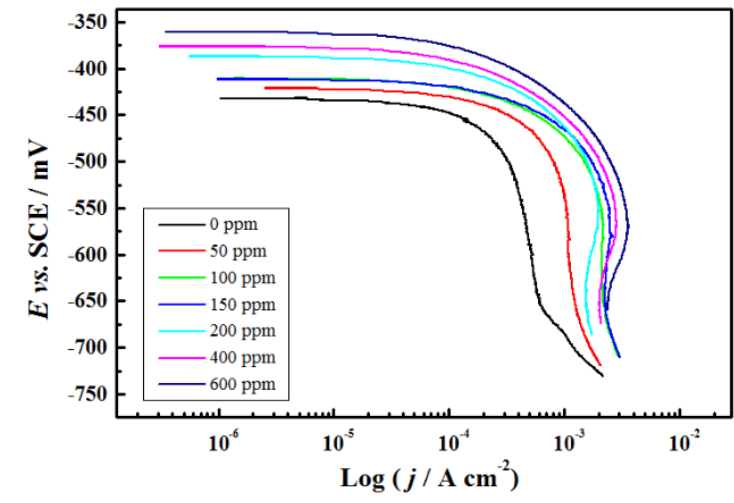

(b)

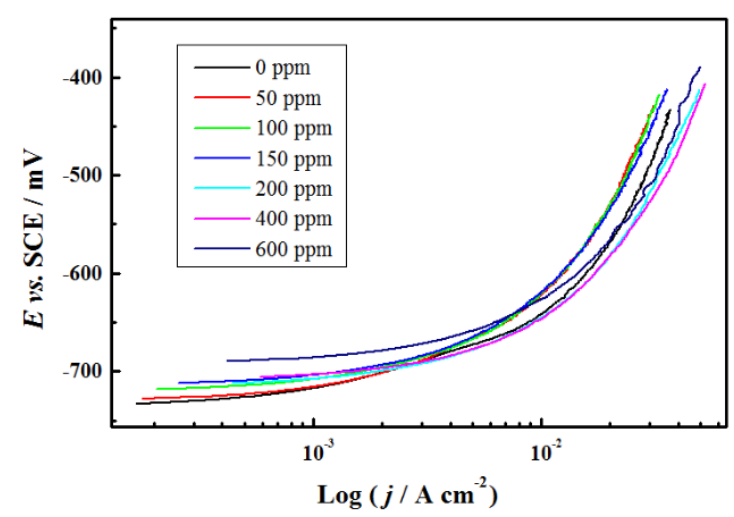

(d)

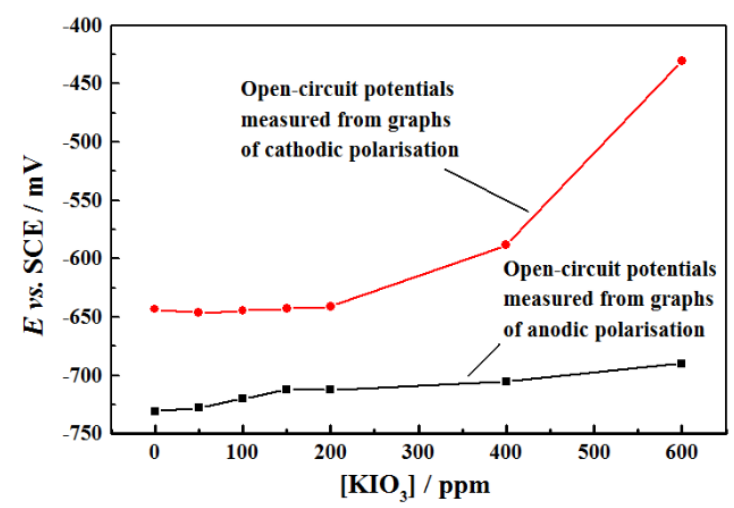

(f)

Fig. 4. (a) Anodic and (b) cathodic polarisation data obtained from an EN coated mild steel RDE surface in a $\mathrm{NiSO}_{4}$ electrolyte at $90^{\circ} \mathrm{C}$ in sodium hypophosphite (sweep rate $=1 \mathrm{mV} \mathrm{s}^{-1}$ ), and (c) open-circuit electrode potentials taken from anodic and cathodic polarisation plots. $\mathrm{KIO}_{3}$ concentrations indicated. (d-f) Show similar plots to (a-c) except that the mild steel RDE has not been EN coated.

\section{Effect of $\mathrm{KIO}_{3}$ additions on a mild steel $\mathrm{RDE}$}

The effect of adding $\mathrm{KIO}_{3}$ on the anodic (Fig. 4d) and cathodic (Fig. 4e) polarisation curves for a mild steel RDE was then investigated. For the anodic polarisation, there was a steady shift in the open-circuit potential (from $731 \mathrm{mV}$ to $-690 \mathrm{mV} v s$. SCE) with increasing $\left[\mathrm{KIO}_{3}\right]$. There was no specific trend in the anodic currents with additive level over the range of stabiliser additions investigated, comparable to the results obtained at the static mild steel electrode. 
Table 2. Plating rates determined from the deposition current density $\left(j_{\text {dep }}\right)$ calculated from the mixed potential $\left(E_{m i x}\right)$ theory and mass gain experiments (at various $\mathrm{KIO}_{3}$ concentrations) at (a) an EN plated mild steel RDE, and (b) and uncoated mild steel RDE.

\begin{tabular}{|c|c|c|c|c|}
\hline$\left[\mathrm{KIO}_{3}\right] / \mathrm{ppm}$ & $j_{\mathrm{dep}} / \mathrm{mA} \mathbf{c m}^{-2}$ & $\begin{array}{c}E_{m i x} \\
\text { vs. } \mathrm{SCE} / \mathrm{mV}\end{array}$ & $\begin{array}{l}\text { Plating rate }{ }^{\mathrm{a}}, \\
\Delta x / t / \mu \mathrm{m} \mathrm{h}^{-1}\end{array}$ & $\begin{array}{l}\text { Plating rate }{ }^{\mathrm{b}}, \\
\Delta x / t / \mu \mathrm{m} \mathrm{h}^{-1}\end{array}$ \\
\hline \multicolumn{5}{|l|}{$\overline{\text { (a) }}$} \\
\hline 0 & 0.2623 & -447.7 & 0.37 & 14.2 \\
\hline 50 & 0.2594 & -413.7 & 0.36 & 14.2 \\
\hline 100 & 0.2975 & -412.4 & 0.42 & 14.0 \\
\hline 150 & 0.3118 & -410.1 & 0.44 & 13.5 \\
\hline 200 & 0.2941 & -391.2 & 0.41 & 13.0 \\
\hline 400 & 0.3749 & -388.1 & 0.52 & 9.2 \\
\hline 600 & 0.4154 & -376.6 & 0.58 & 1.4 \\
\hline \multicolumn{5}{|l|}{$\overline{\text { (b) }}$} \\
\hline 0 & 0.6392 & -684.7 & - & 14.2 \\
\hline 50 & 0.6578 & -683.9 & 0.92 & 14.2 \\
\hline 100 & 0.7056 & -679.8 & 0.98 & 14.0 \\
\hline 150 & 0.6559 & -680.4 & 0.92 & 13.5 \\
\hline 200 & 0.7901 & -684.1 & 1.10 & 13.0 \\
\hline 400 & 1.033 & -675.1 & 1.44 & 9.2 \\
\hline 600 & 5.205 & -616.8 & 7.26 & 1.4 \\
\hline
\end{tabular}

${ }^{a}$ From polarisation data; ${ }^{b}$ From mass gain data

The cathodic polarisation curves showed a similar trend in potential up to $\left[\mathrm{KIO}_{3}\right]=200 \mathrm{ppm}$ (Fig. 4f). Up to this level of additive, the open-circuit potential remained constant at $c a$. $-640 \mathrm{mV} v \mathrm{~s}$. SCE. After $200 \mathrm{ppm}$, the corrosion potential increased from $-640 \mathrm{mV}$ to $-588 \mathrm{mV} v s$. SCE for $400 \mathrm{ppm}$, and to $-430 \mathrm{mV} v s$. SCE at 600 $\mathrm{ppm}$. There was a significant alteration in shape of the cathodic polarisation plot as the level of additive increased above $200 \mathrm{ppm}$ stabiliser. At $400 \mathrm{ppm}$, there was a slight shift in corrosion potential and a reduction in the limiting current. At $600 \mathrm{ppm}$, there was a large shift in corrosion potential and a similar decrease in limiting current. From mass gain measurements, the reduction in limiting current coincided with the reduction in plating rate which also occurred at $400 \mathrm{ppm} \mathrm{KIO}_{3}$.

\section{Mixed potential analysis}

Combining the anodic and cathodic polarisation curves, as was done with the data obtained from the static electrodes, the values of $E_{m i x}$ and $j_{d e p}$ for each solution at an EN and mild steel RDE could be determined (Table 2).

At the EN coated RDE, $E_{m i x}$ shifted gradually from $-447 \mathrm{mV}$ to $-376 \mathrm{mV} v s$. SCE after $600 \mathrm{ppm}$ of stabiliser had been added (Table 2). The value of $i_{\text {dep }}$ also increased steadily from $0.26 \mathrm{~mA} \mathrm{~cm}^{-2}$ to $0.42 \mathrm{~mA} \mathrm{~cm}^{-2}$. At the mild steel RDE, $E_{m i x}$ remained constant up to $200 \mathrm{ppm}$ at $-680 \mathrm{mV} v s$. SCE. $E_{m i x}$ then increased to $-675 \mathrm{mV} v s$. SCE at $400 \mathrm{ppm}$ and to $-616 \mathrm{mV} v s$. SCE at $600 \mathrm{ppm}$. The deposition current also followed a similar trend to $E_{m i x}$, remaining constant at $0.7 \mathrm{~mA} \mathrm{~cm}^{-2}$ up to $200 \mathrm{ppm}$. At $400 \mathrm{ppm}, i_{\text {dep }}$ increased to $1 \mathrm{~mA} \mathrm{~cm}^{-2}$ and at $600 \mathrm{ppm}$, to $5.2 \mathrm{~mA} \mathrm{~cm}^{-2}$.

\section{Conclusions}

The overall deposition reaction of EN is considered to be the combination of two chemical reactions, the reduction of $\mathrm{Ni}^{2+}$ and the oxidation of the reducing agent, sodium hypophosphite. This is represented by reactions (1) and (2). The mixed potential theory can be applied to the study of EN deposition by separating the partial reactants. 
Anodic polarisations, in the absence of $\mathrm{Ni}^{2+}$ and cathodic polarisations, in the absence of hypophosphite ion can be overlapped to give the mixed potential, $E_{m i x}$ and the deposition current density, $j_{d e p}$.

Anodic and cathodic polarisation behaviour was examined at static electrodes and to simulate plating conditions, at an RDE. The mixed potential analysis was carried out at a freshly deposited static electrode with $\mathrm{KIO}_{3}$, a known bath stabiliser, over a concentration range of 0 to $600 \mathrm{ppm}$. Mass gain measurements showed a reduction in plating rate at $400 \mathrm{ppm}$ with almost no plating taking place at $600 \mathrm{ppm} \mathrm{KIO}_{3}$ levels.

The mixed potential analysis showed a large shift in potential at $100 \mathrm{ppm} \mathrm{KIO}_{3}$ with a large reduction in the deposition current density from $4.5 \mathrm{~mA} \mathrm{~cm}^{-2}$ to less than $1 \mathrm{~mA} \mathrm{~cm}{ }^{-2}$ at a freshly deposited EN electrode. At an uncoated mild steel electrode, an initial shift in mixed potential was followed by a gradual increase with the deposition current showing no specific trend. From the deposition current, the plating rate was calculated which showed no correlation to actual plating rates, obtained from mass gain analysis.

To simulate plating conditions, the effect of adding $\mathrm{KIO}_{3}$ on the anodic and cathodic polarisation curves of the partial reactants was carried out at using an RDE. The effects due to agitation used in EN baths could then be shown under reproducible flow conditions. The polarisation curves were carried out using two electrodes, a mild steel RDE coated with high phosphorus EN and a mild steel RDE.

At a mild steel RDE coated with high phosphorus EN both the mixed potential and deposition current increased gradually with $\mathrm{KIO}_{3}$ concentration. The calculated plating rate gave very low results at under $1 \mu \mathrm{m} \mathrm{h}^{-1}$ for all concentrations. At a mild steel RDE there was a large shift in $E_{m i x}$ and $j_{d e p}$ at $400 \mathrm{ppm}$, which coincides with a reduction in plating rate although the trends were opposite to actual plating rates.

Commercial electroless baths usually have between $0-50 \mathrm{ppm}$ of stabiliser added to prevent the random deposition of $\mathrm{Ni}$ onto the sides of the bath and onto dust particles. Examination of the polarisation sweeps indicates that additions of $\mathrm{IO}_{3}{ }^{-}$ion do have an effect on $E_{\text {mix }}$ and the shape of the potential-current plots. The change in $E_{m i x}$ indicates the nature of the surface had altered even at relatively low additive concentrations.

The $\mathrm{IO}_{3}{ }^{-}$ion has been shown to affect both the cathodic (reduction of $\mathrm{Ni}$ ) and anodic (oxidation of hypophosphite) processes although the former is most likely to be the most important in deciding the nature of the stabilising process. The use of mixed potentials to study the effect of additives on EN plating has been shown to be useful when used in conjunction other experiments such as plating rate analysis by mass gain. The results, however, are inconsistant with the plating rate analysis, with the mixed potential changing abruptly at $100 \mathrm{ppm}$, whereas the plating rate fell dramatically at additions above $400 \mathrm{ppm}$ of stabiliser. This indicates that the nature of the surface film is changing at a low concentration of additive whereas the plating rate is not markedly affected.

$\mathrm{IO}_{3}{ }^{-}$additions up to $400 \mathrm{ppm}$ had no influence on the subsequent corrosion resistance or the nature of the protective film on the deposit.

\section{References}

1. M. Paunovic: Plating Surf. Finish., 1983, 70, 62-66.

2. M. Paunovic: Plating, 1968, 55, 1161-1167.

3. M. Paunovic: Electrochem. Sci. Technol., 1977, 124, 349-354.

4. P. Bindra and J. Roldan: J. Appl. Electrochem., 1987, 17, 1254-1266.

5. J.L. Fang and K.P. Han: Plating Surf. Finish., 1997, 84, 91-94.

6. H. Keping and J.L. Fang: Metal Finishing, 1997, 95, (2), 73-75.

7. D. Altura: 'Electrochemical evaluation of electroless nickel plating', Proc. 11th World Congress on Metal Finishing, Interfinish 84, Jerusalem, Israel 1984, 312-321.

8. H. Keping and F. Jingli: Trans. IMF, 1996, 74, (3), 88-90.

9. L. Das and D.T. Chin: Plating Surf. Finish., 1996, 8374, (8), 55-613.

10. P. Bindra, D. Light and D. Rath: IBM J. Res. Develop., 1984, 28, 668-678.

11. C. Gabrielli and F. Raulin: J. Appl. Electrochem., 1971, 1, 167-177.

12. I. Ohno: Mat. Sci Eng. 1991, A146, 33-49.

13. M. Suzuki, N. Sato, K. Kanno and Y. Sato: J. Electrochem. Soc., 1982, 129, 2183-2187.

14. N. Sato, M. Suzuki and Y. Sato: J. Electrochem. Soc., 1983, 130, (7), 1485-1488.

15. S.J. Rose, R.E. Gustar, D.R. Mihara, R.I. Bickley, H.G.M. Edwards and A. Knowles: Trans. IMF, 1993, 73, 11-14. 
16. U. Holmann and K.G. Weil: Plating Surf. Finish., 79, 1992, 60-62.

17. Y. Jin, D. Sun, J. Yu, C. Dong and D. Yang: Trans. IMF, 1999, 77, 181-184.

18. S.M. Mayanna, L. Ramesh and B.S. Sheshadri: Trans. IMF, 1996, 74, 66-68.

19. G.O. Mallory and J. Hajdu: 'Electroless plating: fundamentals and applications', American Electroplaters and Surface Finishers Society, Orlando, Florida, 1990.

20. K.P. Han and J.L. Fang: J. Appl. Electrochem., 1996, 26, 1273-1277.

21. M. Pourbaix: Atlas of Electrochemical Equilibria in Aqueous Solutions. Pergamon Press, Oxford. 1966.

22. D.P. Nikolelis, M.I. Karayannis, E.V. Kordi and T.P. Hadjiioannou: Anal. Chim. Acta, 1977, 90, $209-214$.

23. F.C. Walsh: A First Course in Electrochemical Engineering. The Electrochemical Consultancy, Romsey. 1991.

24. D.A. Pletcher: First Course in Electrode Processes. The Electrochemical Consultancy, Romsey. 1991.

Appendix 1: Determination of the mixed potential of the electrode and deposition current density from polarisation data

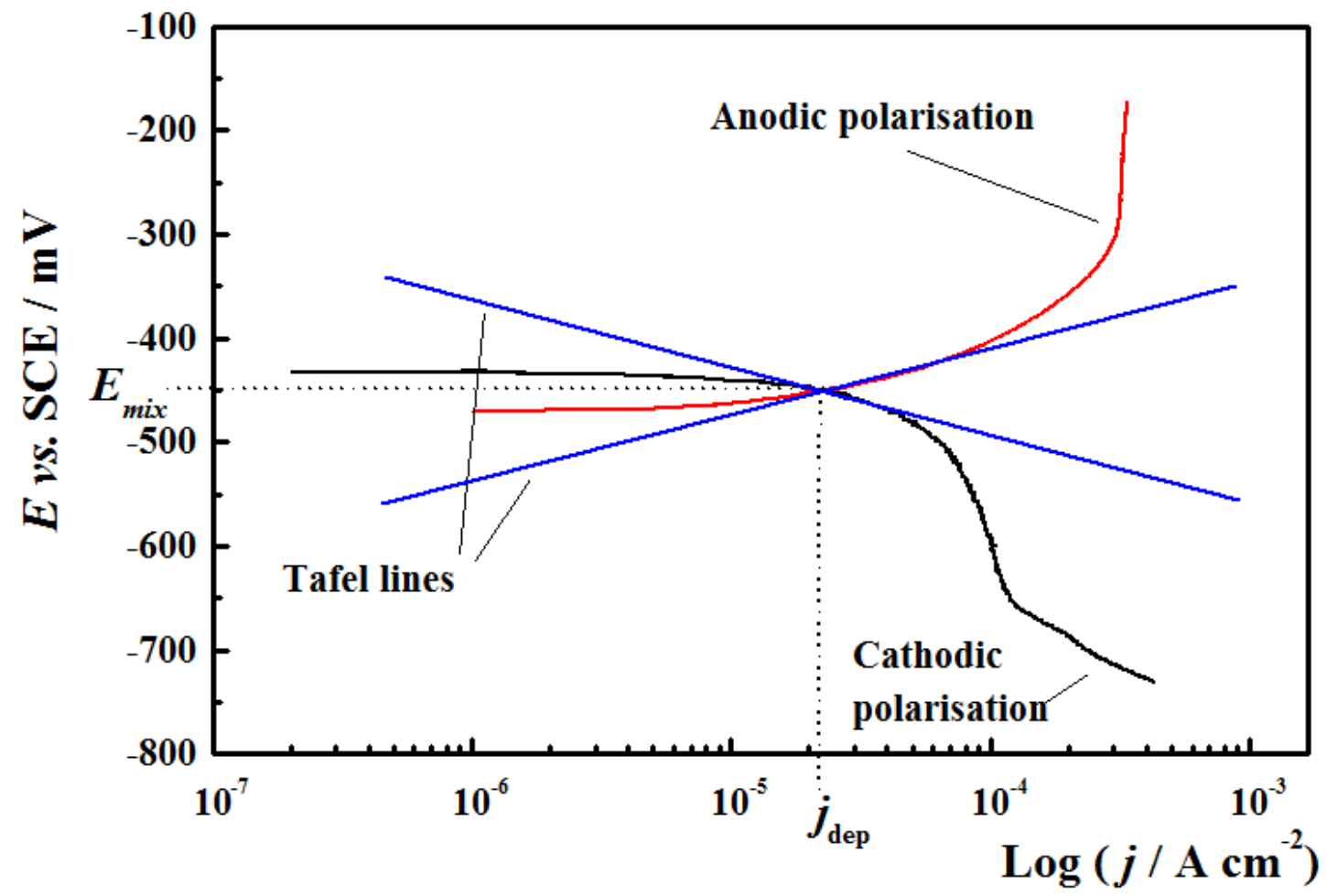

The use of anodic and cathodic polarisation curves to determine the mixed potential and current from extrapolation of the linear Tafel regions. 


\section{Appendix 2: Calculation of mean electroplating rates from Faraday's laws}

Faraday's laws may be summarised as follows:

1. The mass of material $(m)$ formed at an electrode is proportional to the current $(I)$ flowing over time $(t)$ :

$$
m \propto I t
$$

2. The mass of product formed is proportional to the number of electrons $(n)$ :

$$
m \propto \frac{\bar{M}}{n}
$$

Combining these two equations:

$$
m=\frac{K M I t}{n}
$$

where $K$ is a constant

The constant of proportionality is the reciprocal Faraday constant, $F$

$$
m=\frac{1}{F} \cdot \frac{M I t}{n}
$$

The expression can be conveniently written as:

$$
m=\frac{M j_{d e p} t}{n F}
$$

where

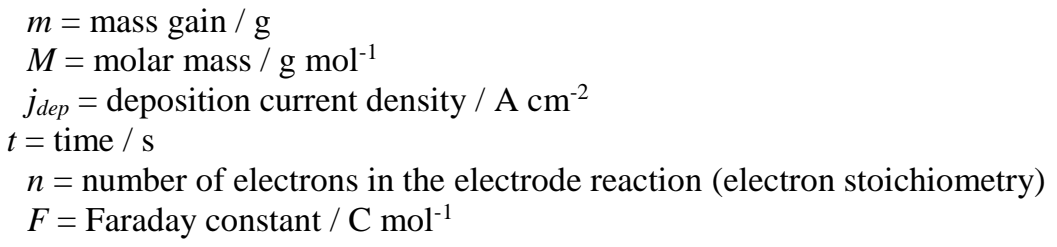

The mean deposit thickness $(x)$ is related to the mass $(m)$ and density $\left(\rho / \mathrm{g} \mathrm{cm}^{-3}\right)$ :

$$
x=\frac{m}{\rho}
$$

\section{Specimen Calculation}

The deposition current density in an electrolyte containing $0.1 \mathrm{M} \mathrm{NiSO}_{4}$ and $0.2 \mathrm{M} \mathrm{NaH}_{2} \mathrm{PO}_{3}$ is $4.38 \mathrm{~mA} \mathrm{~cm}^{-2}$.

$$
\begin{gathered}
\frac{w}{t A}=\frac{58.71 \times 4.38 \times 10^{-3} \times 60 \times 60}{2 \times 96485} \\
\frac{w}{t A}=4.80 \times 10^{-3} \mathrm{~g} \mathrm{~cm}^{-2} \mathrm{~h}^{-1} \\
x=\frac{4.80 \times 10^{-3}}{7.85} \mathrm{~cm} \\
x=6.10 \times 10^{-4} \mathrm{~cm} \\
x=6.10 \mu \mathrm{m}
\end{gathered}
$$

